\title{
TROCADILHO: O PRIMO POBRE DA CRIAÇÃO PUBLICITÁRIA
}

\author{
Pun: The cousin's poor of advertising creating
}

\section{Juego de palabras: el primo pobre de la créación publicitária}

Celso Figueiredo Neto ${ }^{1}$

\section{Resumo}

Este artigo visa resgatar o trocadilho como ferramenta retórica de criação publicitária amplamente utilizada, com frequência como recurso humorístico, nem sempre bem recebida pelos criativos e intelectuais. Uma análise da presença do humor na publicidade, bem como do uso extensivo de trocadilhos textuais e visuais justifica uma abordagem mais minuciosa do fenômeno. O levantamento bibliográfico indica que os critérios existentes não servem ao propósito de verificar o potencial persuasivo dos trocadilhos, para tanto, propomos como critérios a eficácia e a originalidade para avaliar as referidas figuras de linguagem. Por eficácia entenderemos a capacidade dos múltiplos sentidos do trocadilhos contribuírem para a construção do sentido; por originalidade o afastamento do universo dos clichês que esvazia a riqueza semântica do fenômeno.

Palavras-chave: humor, publicidade, retórica, criação publicitária.

\begin{abstract}
This article aims to rescue the pun as a rhetorical tool for creative advertising where it is widely used, often as a humorous resource, but not always well received by the creative and intellectual players. An analysis of the presence of humor in advertising as well as the extensive use of textual ans visual puns justify a more detailed approach of the phenomenon. The literature indicates thar the existing criteria do not serves the purpose of verifying the pontential of persuaviness of a pun. To this end we propose a different criteria, based in originalty and effectiveness. The evectiveness can be verified by the evaluation of as the various senses of the word contribute to de construction of a
\end{abstract}

\footnotetext{
${ }^{1}$ Doutor em Comunicação e Semiótica pela PUC-SP, professor pesquisador do Centro de Comunicação e Letras da Universidade Presbiteriana Mackenzie, faz parte do núcleo estruturante do Mestrado em Comunicação dessa Universidade. kekofig@gmail.com
} 
Trocadilho: o primo pobre da criação publicitária

de Celso Figueiredo Neto

significant. The originality is based on the distancing of the cliché, since the obvious pun would remove the semantic richness of the phenomenom.

Keywords: Humor, Advertising, Rhetoric, Creativity

\section{Resumen}

Este artículo tiene como objetivo rescatar el juego de palabras como una herramienta retórica para la creación de la publicidad utilizada como un recurso a menudo humorístico que no siempre es bien recibido por la gente que trabaja com la creatividad e por los intelectuales. Un análisis de la presencia del humor en la publicidad, así como el uso extensivo de juegos de palabras textuales y visuales puede justificar un enfoque más detallado del fenómeno. La literatura indica que los criterios existentes no cumplen con el propósito de verificar el potencial de los juegos de palabras persuasivas, con este fin, se propone como la eficacia y los criterios de originalidad para evaluar estas figuras de lenguaje. Eficacia de entender la capacidad de los múltiples significados de los juegos de palabras contribuyen a la construcción del significado, para la eliminación del universo original de clichés que vacía la riqueza semántica del fenómeno.

Palabras-clave: Humor, Publicidad, Retórica, Creación Publicitaria

\section{INTRODUÇÃO}

Filósofos não riem. A complexidade dos objetos não permite distrações. A busca pelo bem e pela verdade é por demais importante para ser desviada por graças e devaneios que possam comprometer a clareza do pensamento com distorções interpretativas próprias da polissemia do humor.

O parágrafo que abre esse texto é um exemplo rematado do pensamento majoritário acerca do humor. Esse pensamento, segundo Geier (2011) é o resultado de uma conjunção de fatores que tem entre seus principais componentes o fato de Platão ser um dos pais do pensamento ocidental. Não obstante a importância inquestionável da obra do mestre grego, o filósofo alemão tem como hipótese que, se a história tivesse sido diferente e não fosse a obra de Platão que tivesse sobrevivido ao tempo, mas a de outro pensador mais afeito ao riso como Xenofonte ou Demócrito talvez a relação da filosofia com o humor fosse diferente, mais amigável talvez.

É difícil enfrentar dois mil anos de tradição em nome de um "se", é verdade. E este artigo não objetiva retomar a discussão filosófica proposta por Geier, mas dela 
Trocadilho: o primo pobre da criação publicitária

de Celso Figueiredo Neto

partir para tentar lançar um pouco de luz em uma sub categoria do humor, talvez a mais mal-falada delas, para tentar, por meio de uma análise científica, avaliar até que ponto sua má fama procede e até que ponto é fruto de certo "desprezo" cultural do qual merece resgate.

Trata-se do trocadilho, visto por muitos como o mais baixo tipo de humor, por outros como um grande "portal" do humor, pelos publicitários desesperados como uma bóia de salvação no final da tarde, uma piadinha banal que "resolve" um anúncio, para outros como grosseira apelação sem sentido. Há ainda quem os adore, adote, colecione e repita. Trocadilhos, como se vê, são um tema deliciosamente controverso, amplamente utilizado na publicidade e no cotidiano mas pouco estudado por lingüistas ou pensadores vinculados aos processos de comunicação.

\section{HUMOR NA PUBLICIDADE}

A publicidade, diferente da filosofia, tem bom relacionamento com o humor. $\mathrm{O}$ humor é bem recebido e reconhecido como um dos propulsores. Em editorial da revista Meio \& Mensagem de 12 de dezembro de 2011, a jornalista Regina Augusto faz uma retrospectiva dos cinco fatos mais relevantes da publicidade mundial em 2011 e dentre estes, dois, o comercial The Force da Deutsch LA para Volkswagen e a campanha Pôneis Malditos da Lew Lara/TBWA para Nissan. Em ambos os casos o recurso retórico do humor aparece como fator fundamental para o sucesso comunicacional da peça publicitária.

No caso do The Force, veiculado pela primeira vez no intervalo mais caro da televisão mundial, o superbowl, a final com campeonato de futebol americano, narra a história de uma criança fantasiada de Darth Vader, o personagem de Guerra nas estrelas, que tenta usar "a força" para mover os objetos da casa, sem sucesso. Até que seu pai chega com um veículo Volksvagem. A criança nem dá atenção ao pai e tenta aplicar sua "força" ao carro. O pai notando o esforço do filho entra na brincadeira e aperta o botão na chave do carro que aciona o motor. Assustado com o próprio poder o pequeno Darth Vader, olha para os lados confuso. Já no comercial dos Pôneis malditos, um jovem percebe seu carro atolado, sai do mesmo xingando, abrindo o motor e dizendo "pôneis malditos". Ao levantar o capô surge a inesperada cena de um parquinho de pequenos pôneis que dançam e cantam alegremente em absoluto contraste com a situação rústica externa. Para piorar o pônei ainda dá um beijo no rapaz dizendo "te quiero". Corta para 
informações da picape Frontier da Nissan com a mensagem de que esta tem cavalos de verdade e por isso não deixaria o condutor na mão em uma situação em que o veículo seja mais exigido. Na versão para internet, esse comercial ainda apresenta a chamada "maldição do pônei." Ao final do comercial, surge novamente o animal, dessa vez com olhos injetados e voz cavernosa lançando sua maldição: "se você não mandar esse email para 10 pessoas vai ficar com essa musiquinha na cabeça" e então repete a melodia infantilizada do início do comercial.

Não obstante o fato do humor ser amplamente utilizado no universo publicitário, em especial no Brasil, país reconhecido em festivais internacionais como criativo, irreverente e bem humorado, a pesquisa científica em comunicação pouco avançou nessa questão. Há inúmeras menções à presença do humor nas peças publicitárias e campanhas analisadas nos trabalhos apresentados em congressos, encontros, simpósios. Há alguma menção à sua importância em obras de autores que tratam do tema (Hoff e Gabrielli 2004), (Figueiredo 2005) mas sempre de modo tangencial.

Nossa pesquisa que abrange a imensa gama de recursos retóricos com vistas à persuasão, sendo esses recursos divididos como sub categorias das grandes categorias originais nomeadas por Aristóteles (2002): Ethos, Pathos e Logos. Dentro da categoria Pathos, originalmente ligada ao público, aquela dimensão do orador que garante rapport com o auditório por meio da conexão emocional, enfocamos o humor como um dos mais frequentes modos de penetrar no coração das pessoas evitando que se ergam barreiras contra nosso discurso, ou segundo Elmira Djafarova: "Humor can also be persuasive by relaxing the listener's attitude and so prevent him or her from noticing some detail that he or she might resist."2 (Djafarova 2008, p. 268).

Não existem dados disponíveis que correlacionem o desempenho de campanhas publicitárias que se utilizem de humor e seus resultados de marketing. Temos porém, campanhas inesquecíveis que se alimentaram desse recurso, algumas delas, inclusive, lançando bordões que por anos ficaram na boca do povo. São exemplos disso a campanha das camisas USTop, que com humor demonstrou a ascensão profissional do Sr. Fernando até a confortável posição de "bonita camisa, Fernandinho", junto ao presidente da empresa. Rimos e repetimos "dá pra tomar uma Kaiser antes” dos pedidos mais malucos que nos são feitos, fizemos "cara de conteúdo" quando não sabíamos do que se tratava ou não achávamos as coisas “assim, uma Brastemp”. Esses, exemplos de

\footnotetext{
${ }^{2}$ Humor também pode ser persuasivo, relaxando a atitude do ouvinte e assim evitar que este note algum detalhe ao qual possa resistir. [trad. Nossa]
} 
Trocadilho: o primo pobre da criação publicitária

de Celso Figueiredo Neto

bordões que se alimentaram do humor para marcar épocas. Mas outras campanhas adoráveis também se basearam nessa ferramenta persuasiva, dentre elas a mais longeva da publicidade mundial, o garoto Bombril, com sua delicada ingenuidade vem alegrando as donas de casa nas noites de domingo há mais de 30 anos. Cães bassé para Cofap, gordinhos para Embratel, ilha quadrada para Skol, são inúmeros os casos em que o humor apoiou campanhas de sucesso na publicidade.

Dentre das variadas maneiras de se fazer humor escolhemos investigar o "primo pobre" da criação publicitária e do humor. Esse pária, tão mal visto quanto freqüente, a exemplo do próprio humor diante da filosofia, merece redenção diante da academia. Esse é o intuito do presente texto. Como o humor ele continuou existindo não obstante os diversos esforços da alta cultura/criatividade pela sua extinção alegando baixo nível de complexidade semântica ou semiótica, pouca inteligência, desimportância. Como o humor o trocadilho sobreviveu e agradou aos públicos menos comprometidos com uma estética "purista". Se na filosofia reinou Platão. Na publicidade contemporânea a elegância gráfica de Bill Bernbach com seu humor sutil, as chamadas "cócegas na inteligência" deram o tom do que seria desejável na criação dita sofisticada.

Há, contudo, um imenso contingente de peças publicitárias e de consumidores, que em última instância sustentam o mercado publicitário, que bebem de outra fonte, outro dos chamados pilares conceituais da publicidade, o norte-americano Rosser Reeves (Roman 2011). O redator que veio a se tornar presidente da Young \& Rubican, uma das maiores agências e propaganda do mundo, e criador do conceito USP, Unique Selling Proposition, (Proposta Única de Vendas) trabalhava em um patamar diferente de comunicação, no varejo, no qual o esforço publicitário é prioritariamente dirigido à transmissão da mensagem de vendas do produto anunciado.

\section{O TROCADILHO}

No universo do varejo atual, vemos amiúde o uso de trocadilhos. Já nas elegantes peças publicitárias de construção de marca, o uso dos trocadilhos é mais discreto, pois parece haver pejo de usá-lo; nessas, porém, o trocadilho visual é utilizado em larga medida; esses, curiosamente, são aplaudidos no cenário glamouroso dos festivais e premiações publicitárias, como veremos adiante.

Uma revisão bibliográfica das obras em português não apresentou nenhum texto que trate especificamente da questão. Em língua inglesa começamos a encontrar 
Trocadilho: o primo pobre da criação publicitária

de Celso Figueiredo Neto

referências já em forma de trocadilho, pois naquela língua o termo que designa trocadilho é pun.

Trocadilho, define o dicionário Houaiss eletrônico, é “jogo de palavras que apresentam sons semelhantes ou iguais, mas que possuem significados diferentes, de que resultam equívocos por vezes engraçados" ou "uso de expressão que dá margem a diversas interpretações”. Ex. Exportar é o que importa (Delfim Netto) Já Cunha (1986, p.792) sugere uma etimologia do Castellano, 1890, trocadilla, que conduziria a uma interpretação distinta na qual o jogo de palavras serviria ao equívoco, à ilusão, ao engodo antes do humor.

Segundo Radamés Manosso, a tradição lingüística costuma tipificar os trocadilhos em três grupos: fonológicos, em que se agrupam todas as variantes de equívocos possíveis a partir de eufonias, como "por cada" e "porcada" ou "concerto" e "conserto" ou polissêmicos como as várias acepções possíveis para a palavra manga. O segundo tipo de trocadilho é o sintático, que por inversão da posição do termo na frase, e/ou sua função sintática levará à mudança de sentido, assim expressões como "ou o Brasil acaba com a saúva ou a saúva acaba com o Brasil" exemplificam esse tipo de trocadilho. Finalmente, temos o grupo dos semânticos, baseados no sentido, que podem inverter signo por significado, repetir termo, fazer uso de elipses e assim por diante. Exemplifica-se esse grupo com a frase: "em vão os sonhos se vão".

$\mathrm{Na}$ literatura estrangeira, o clássico artigo de McQuarrie e Mick (1996) é sempre citado como paradigmático transpositor da teoria retórica para a práxis da publicidade. Nele os autores apresentam uma bem escolhida série de anúncios com os quais exemplificam cada uma das figuras de linguagem e demonstram como os recursos retóricos fazem parte do dia a dia do fazer publicitário. Djafarova (2008) lembra que muitos apontaram a frequente presença de figuras retóricas nos títulos de peças publicitárias, dentre eles (Leight 1994) que afirma haver figuras de estilo em $74 \%$ dos títulos de anúncios. A autora nota também que mesmo na avançada pesquisa norteamericana na área de comunicação, não se encontram escritos específicos acerca da farta presença dos trocadilhos na publicidade. Djafarova discorre sobre as questões que levam ao uso dos trocadilhos apresentando argumentos como o fato de que o emissor e o público compartilham um mesmo universo de referências de modo que o duplo sentido do trocadilho possa ser compreendido. Segundo a autora as razões do uso do trocadilho são: evitar o tédio e economizar espaço já que o duplo sentido de um 
Trocadilho: o primo pobre da criação publicitária

de Celso Figueiredo Neto

trocadilho traria ao título a possibilidade de dizer duas mensagens em uma mesma sentença.

\section{UM OLHAR MAIS PUBLICITÁRIO}

Em nosso entender, o fato de emissor e público compartilharem referências, para que o trocadilho seja compreendido, nada mais é que habilidade intrínseca à tarefa do redator publicitário. Não é possível redigir com eficiência em publicidade se não se souber penetrar no universo de referências do público alvo e construir no texto uma bricolagem dessas referências associando-as ao produto anunciado (Carrascoza 2003). É portanto, condição sine qua non, à atividade publicitária "falar a língua do consumidor" não havendo necessária ou direta relação com o domínio da técnica trocadilhesca. Em termos de economia de espaço entende-se que esta não seria o fator principal, determinante, do uso de trocadilhos na titulação de anúncios, pois não há direta correlação entre capacidade de síntese e habilidade para criação de textos ambíguos.

Neste ponto é preciso estabelecer um critério de valor em relação aos trocadilhos. A diferenciação oferecida pela regra da língua é regida pela forma, que nesse caso, não nos auxilia na questão da persuasão. Por esse motivo, faz-se necessária a criação de um diferente critério para caracterizar a eficiência publicitária do fenômeno aqui estudado.

Poderíamos dizer que existem trocadilhos melhores que outros e o critério que regeria essa qualificação seria a) a eficácia, no sentido de que as duas ou mais acepções do trocadilho contribuam para a construção do sentido da mensagem a ser transmitida e b) a originalidade, que esse trocadilho não seja clichê. Trocadilhos clichetados são tão comuns em publicidade que passam desapercebidos pelo consumidor: "festival de ofertas" "preços de arrasar" "queima de estoque" e demais fórmulas desgastadas pelo uso derrubam a dimensão que consideramos a mais relevante no uso desse recurso retórico.

Do nosso ponto de vista a mais importante contribuição do trocadilho na mecânica comunicativa da publicidade é que ele empresta à expressão novas dimensões. Pode-se dizer que quanto mais sentidos possam ser extraídos de uma sentença mais amplas são as possibilidades comunicativas ou a complexidade da mensagem. São,

portanto, diferentes acessos cognitivos utilizados simultaneamente no intuito de persuadir o consumidor acerca da mensagem que se quer transmitir. Seja pelo humor, 
pelo inesperado da associação proposta na sobreposição de sentidos, o trocadilho trará esse "empilhamento" cognitivo que tende a melhorar as "chances" de uma mensagem chegar ao consumidor. Desse ponto de vista, não é errado dizer que um trocadilho sempre será mais rico semanticamente que uma frase que informa objetivamente a mensagem. Daí poderíamos extrair que, não obstante as questões de gosto, moda ou estética, o trocadilho tende a ser mais eficiente como transportador de mensagens.

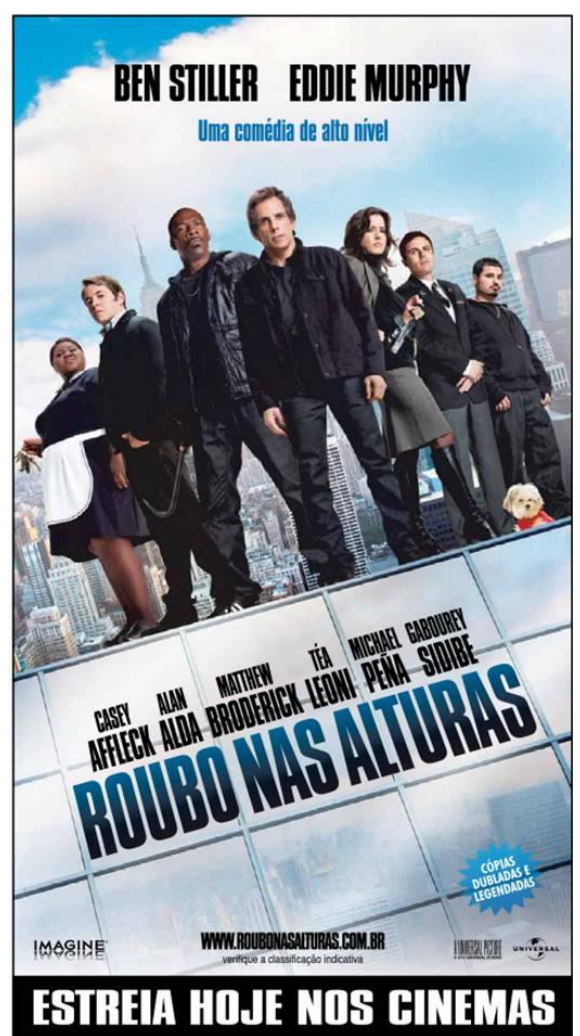

Fig. 1

Fonte: O Estado de S. Paulo 17/12/2011

Vejamos alguns exemplos. Em primeiro lugar, selecionamos trocadilhos de baixo impacto em que sua ambiguidade é quase imperceptível aos olhos do púbico final. Nesse caso entendemos que seria mais uma questão do que como redatores tratamos como "rede semântica" do que propriamente como trocadilho, ou seja, um texto publicitário de boa qualidade deve ser redigido dentro do universo semântico condizente com o tema do produto/serviço anunciado ou com seu público alvo. O título do anúncio "Uma comédia de alto nível" tem direta relação com o título do filme: Roubo nas Alturas. Como trocadilho, é rasteiro e não adiciona uma perspectiva diferente em relação à mensagem "é uma boa comédia", poderemos caracterizá-lo como trocadilho de baixo impacto. 
O refrigerante Mineirinho ao lançar sua versão light usou e abusou de trocadilhos na versão abaixo. Como se vê, o uso do trocadilho nessa campanha está diretamente correlacionado a um segundo nível de expressão. A marca espera que o consumidor compreenda a mensagem, já que sem o entendimento do "segundo" sentido o título do anúncio perderia o senso. Assim, zero a zero na balada joga com a dupla: não conseguir ficar com ninguém e refrigerante zero; o combate ao açúcar passa a ser desnecessário pois o refrigerante é zero; o surfista corta ondas como corta açúcar. Duplo sentido, mais amplitude de mensagem, adição de humor à comunicação.
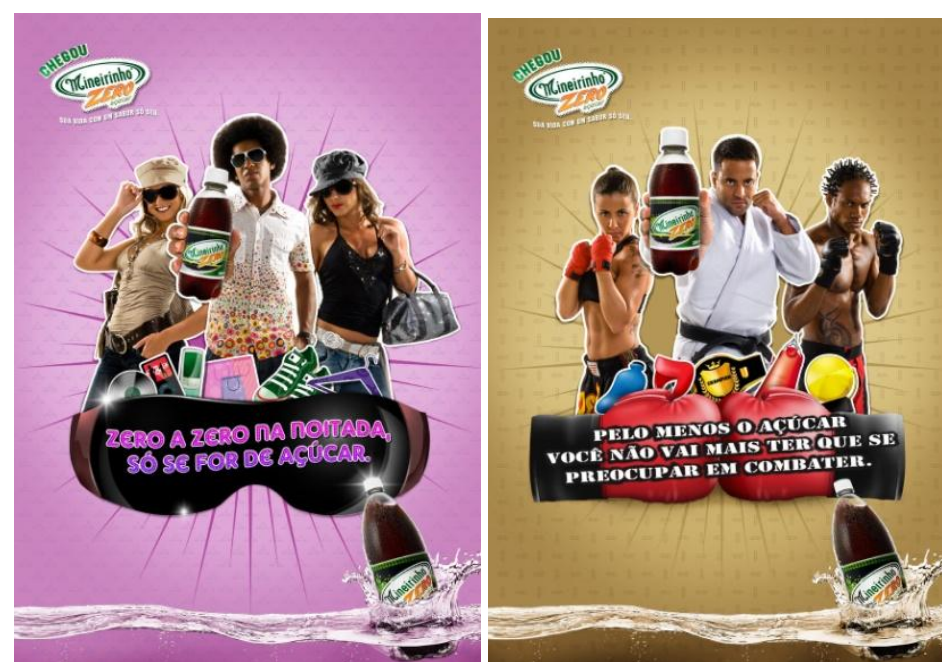

Fig. 2

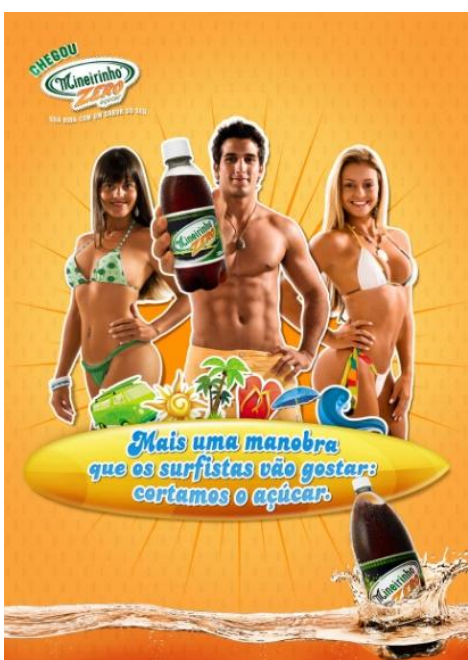

Fonte: www.adsoftheworld.com coletado em 20/12/2011

Outra campanha que merece nossa atenção é a veiculada pela Gráfica Optagraf que exige maior repertório de seu público alvo. Considerando-se ser este público composto por publicitários que tendem a ter nível cultural acima da média a solução até parece boa. Entretanto, a correlação entre os dois sentidos do trocadilho é absolutamente gratuita, vejamos: 

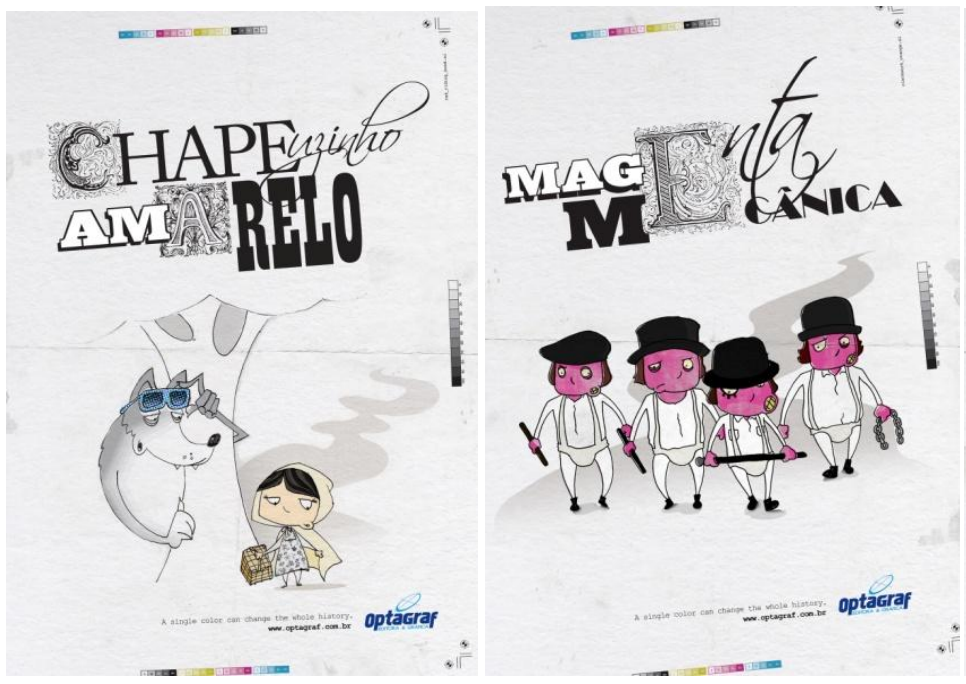

Fig. 3

Fonte: www.adsoftheworld.com coletado em 20/12/2011

Chapeuzinho Amarelo, Magenta Mecânica, A Pantera Desbotada. Uau! A assinatura da campanha,capturada de um site internacional "A single color can change the whole history". ${ }^{3}$ Bem, como sabemos a cor, não mudaria nada em nenhuma das histórias mencionadas, portanto o eixo criativo dessa campanha é bastante frágil. $\mathrm{O}$ trocadilho, nesses casos, é eficaz, até pelo absurdo, na função de capturar a atenção do leitor, claro que ao ser inconclusivo na mensagem a peça publicitária como um todo acaba por trabalhar contra a marca, mas como nosso objeto de análise aqui é apenas o uso dos trocadilhos, concentremo-nos neles. No caso, não há eficácia já que há dúvida de que se possa extrair algum outro sentido, além do óbvio "as cores estão erradas".

Com eficiência a Revista Rolling Stone, veiculou uma campanha bastante agressiva fazendo uso intensivo de trocadilhos. Embora a campanha tenha sido veiculada no Brasil, temos apenas sua versão em Inglês.

\footnotetext{
${ }^{3}$ Uma única cor pode mudar toda a história [trad. Nossa]
} 

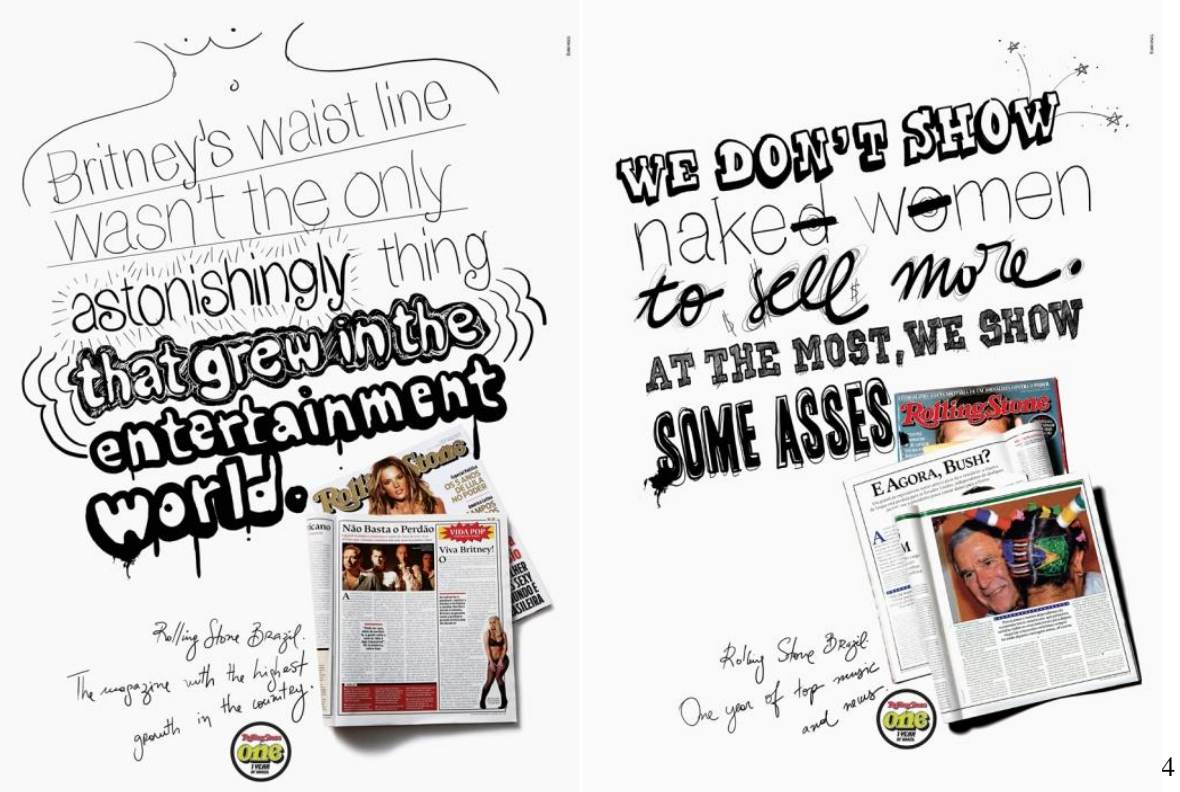

Fig. 4

Fonte: www.adsoftheworld.com coletado em 20/12/2011

Aqui, o uso bem humorado, ainda que crítico e agressivo da cantora/celebridade Britney Spears e do ex presidente Norte Americano George Bush, ambos em trocadilhos beneficiando as características da revista são exemplos de eficácia no uso da ferramenta, já que adicionam novas dimensões cognitivas com o inesperado das correlações entre os termos e as características ressaltadas: obesidade - crescimento de vendas; bundão notícias sobre política.

Outra situação interessante para o do trocadilho é quando ele é utilizado para estabelecer dois níveis de comunicação, um nível genérico, e um segundo pertencente ao grupo que domina conhecimentos específicos, ou que comunga de hábitos próprios. Vejamos o caso abaixo.

\footnotetext{
${ }^{4}$ A cintura da Britney não é a única coisa que cresceu absurdamente no mundo do entretenimento. Rolling Stone a revista com maior crescimento no país.

A gente não mostra mulher pelada para vender mais. No máximo mostramos alguns bundões. Rolling Stones um ano das melhores músicas e informações. [trad. Nossa]
} 


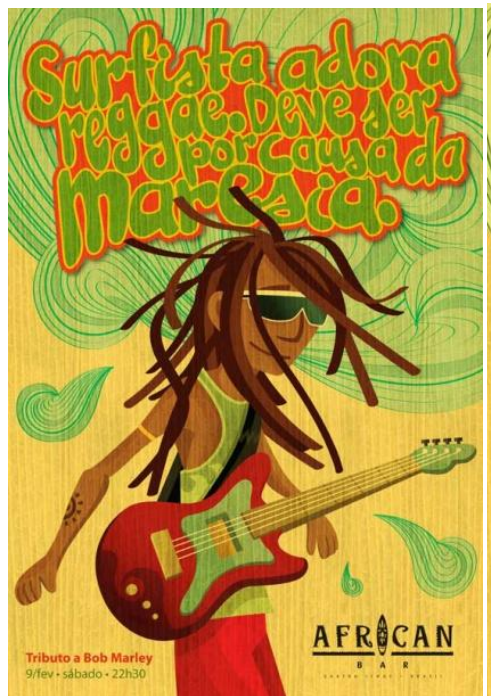

AFR CAN

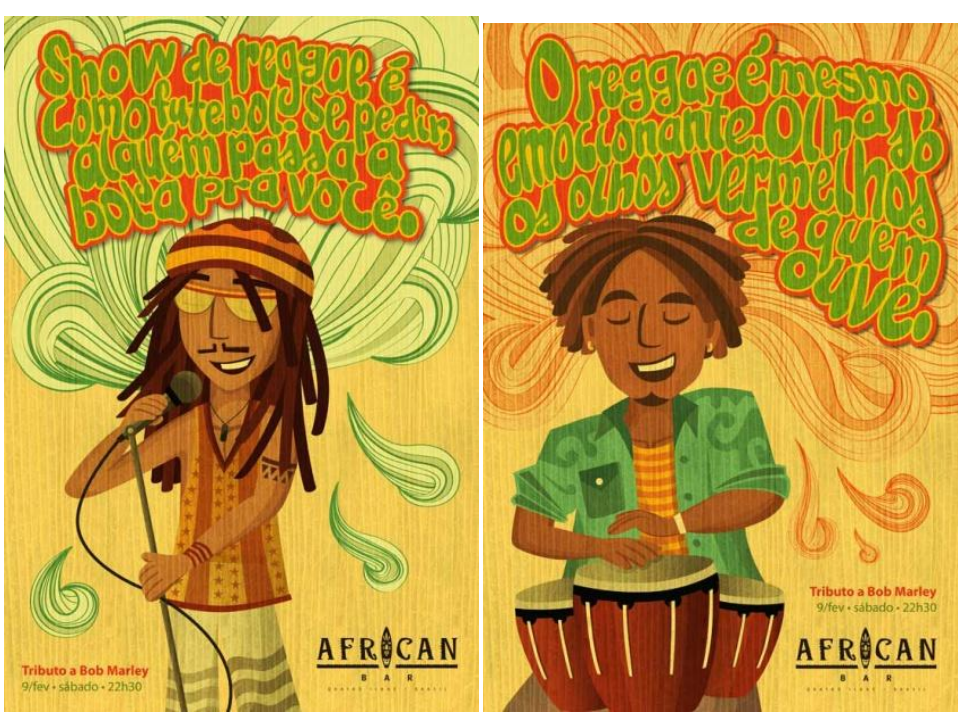

Fig. 5

Fonte: www.adsoftheworld.com coletado em 20/12/2011

A publicidade de um certo African Bar estabelece dois níveis de linguagem, um primeiro, mais simplificado aludindo às belezas e à emoção da música jamaicana. Uma segunda, para ser compreendida apenas por aqueles que compreendem as gírias dos que consomem maconha, com referências explícitas ao uso da erva. Temos então no primeiro título: "Surfista adora reggae. Deve ser por causa da maresia." O termo "maresia" aqui com dupla significação, o ar marinho e o cheiro de maconha sendo queimada. "Show de reggae é como futebol. Se pedir alguém passa a bola para você" A "bola", polissêmica, refere-se ao cigarro de maconha. "O reggae é mesmo emocionante. Olha os olhos vermelhos de quem ouve" Mais uma vez, fica com os olhos vermelhos quem chora, mas também é sintoma de quem fumou maconha.

Finalmente, o trocadilho visual, esse bem quisto e recebido nos melhores salões da publicidade mundial, por vezes se apresenta de uma pobreza criativa monástica. Vejamos a campanha abaixo criada para a rádio especializada em rock'n roll clássico, a Kiss FM, tradicional emissora de São Paulo. 


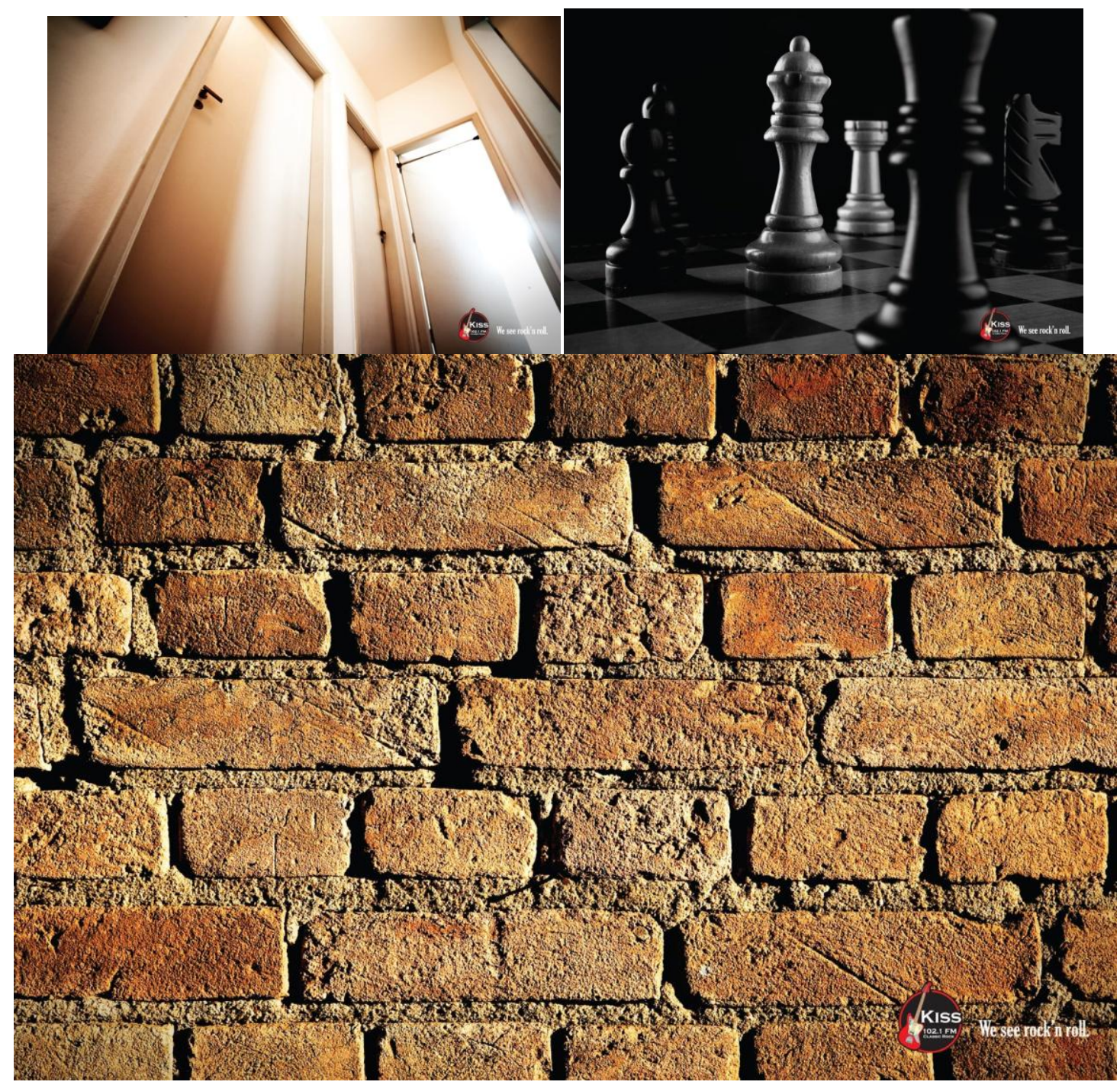

Fig. 6

Fonte: www.adsoftheworld.com coletado em 20/12/2011

As portas remetem ao grupo The Doors, a cena do jogo de xadrez com a rainha em foco faz menção ao Queen, e a parede de tijolos não poderia deixar de ser o famoso disco do Pink Floyd, The Wall. A assinatura da campanha: "we see rock'n'roll”, nós vemos rock'n'roll remete à ideia de obsessão pelo rock, até interessante, a maneira de expressar, contudo, não adiciona novos signos que complementem a significação. Assenta-se na óbvia tradução literal do título da música ou da banda, sem adição de quaisquer referências que enriqueçam a mensagem.

Nesse sentido, pode-se dizer que o fato do trocadilho visual ser naturalmente mais valorizado que o textual, deve ser revisto. É claro que temos peças brilhantes visuais, mas há também muita estultice em cuja ausência de texto se esconde a falta de ideia. É preciso, antes de tudo, observar com mais cuidado os níveis significantes 
presentes na peça sejam eles visuais ou textuais. O grande jogo de "adivinha" que um trocadilho pode propor e que o consumidor, envolvido pode entrar para adivinhar a resposta é uma excelente estratégia de interatividade, entretenimento, aumento de recall e relacionamento entre marcas e consumidores. Apenas para ficar no exemplo mais famoso, a peça vencedora do grand prix de Cannes, propõe uma imensa rede de significações ao alinhar a tampa do Guaraná Diet ao umbigo da modelo. Não apenas mostra que o produto não compromete sua forma física, mas é umbilicalmente apresentado como o princípio para o sucesso na busca da forma perfeita. Nessa expansão interpretativa, o trocadilho visual é uma segura estratégia de provocação para jogo de adivinha entre os consumidores. Esse lado lúdico, como bem demonstrou Huizinga (2007, p. 57) desperta a "essência do lúdico" ou a percepção de que "há alguma coisa em jogo" e que o êxito do jogador dá a ele uma sensação de prazer ou mesmo de pertencer ao grupo dos vencedores (idem, p. 58). Nesse contexto, decodificar um trocadilho, textual ou visual, é resolver um enigma que granjeia uma espécie de prazer ao espectador e tem como efeitos periféricos o aumento da simpatia pela marca (já que ela foi veículo do seu prazer e ascensão ao grupo dos vencedores) e melhora o índice de lembrança da marca, pois o consumidor passou mais tempo com o anúncio na tentativa de decodificá-lo.

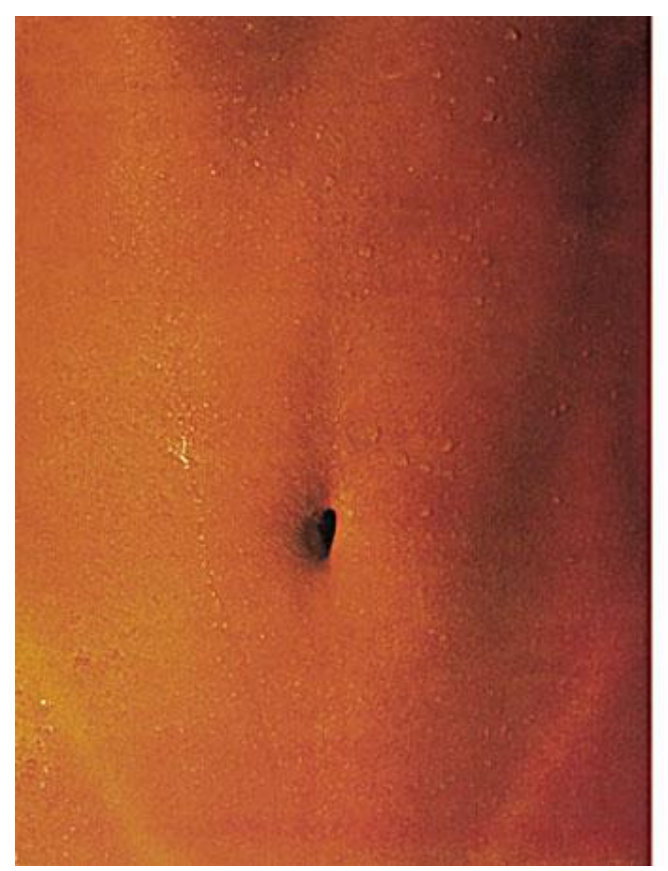

Fig.7

Fonte: www.ccsp.com.br coletado em 20/12/2011

\section{CONSIDERAÇÕES FINAIS}


Como se pode verificar há trocadilhos bons e maus. Sejam eles visuais ou textuais. O que é impossível é que se façam generalizações como temos observado com frequência os narizes torcidos em relação aos trocadilhos textuais. Trocadilhos ineficazes, ou seja, aqueles em que os demais sentidos não contribuem para a construção da mensagem, esses realmente são pobres e provavelmente os responsáveis pela má fama que contaminou toda a categoria. São os trocadilhos gratuitos, em geral, eufônicos e que costuma maquiar a falta de conceitos criativos que sustentem uma campanha publicitária consistente.

Por outro lado, no tiroteio de informações em que vivemos, em que as marcas lutam vorazmente pela atenção do consumidor, a possibilidade de provocá-lo para o jogo lúdico de adivinha, de fazer uma piada rápida ou de entregar vários sentidos em uma única sentença é uma oportunidade que não deve ser desperdiçada. Os trocadilhos, que são associados à comunicação popular não precisam ser a ela restritos. Na medida em que seu constructo se sofistica, nada deixa a desejar em relação aos outros recursos retóricos, pelo contrário. Trata-se de uma ferramenta de impacto que, por sua ampla utilização nos leva a crer que tem oferecido bons resultados. Um teste empírico seria recomendado para quantificar seu efeito.

Este texto serve como uma introdução ao tema, um primeiro mergulho. Estudos mais aprofundados, preferencialmente empíricos, podem ser desenvolvidos para que se verifique o nível de eficácia dos trocadilhos bem como sua compreensão por parte dos consumidores. Um teste de rejeição junto a consumidores $\mathrm{X}$ publicitários também poderia trazer resultados interessantes. Nossa intenção principal nesse artigo foi chamar a atenção para certo descaso com que essa ferramenta retórica tão freqüente vem sendo tratada em meios acadêmicos e, quem sabe, estimular outros estudiosos a achar graça nos trocadilhos. Que a partir desse texto, o preconceito existente em relação aos trocadilhos deixe de lado o pré, mantenha o conceito, faça um conserto no conceito que orquestre um concerto retórico.

\section{REFERÊNCIAS BIBLIOGRÁFICAS}

ARISTÓTELES. Arte Retórica e Arte Poética. $15^{\mathrm{a}}$ ed. Rio de Janeiro: Ediouro, 2002. CARRASCOZA, João A A Evolução do Texto Publicitário Futura 2003 São Paulo 
Trocadilho: o primo pobre da criação publicitária

de Celso Figueiredo Neto

CUNHA, Antonio Geraldo da. Dicionário Etimológico Nova Fronteira da Língua Portuguesa. $2^{\text {a }}$ Ed. Rio de Janeiro 1986

DJAFAROVA, Elmira. 2008. "Why Do Advertisers Use Puns? A Linguistic Perspective." Journal Of Advertising Research 48, no. 2: 267-275

FIGUEIREDO, Celso. Redação Publicitária: Sedução pela Palavra.1a ed. Thomson, São Paulo, 2005

GEIER, Manfred. Do Que Rien as Pessoas Inteligentes. $1^{\text {a }}$ Ed. Rio de Janeiro 2011

HOFF e GABRIELLI, Tania e Lourdes. Redação Publicitária. $1^{\mathrm{a}}$ Ed. Elsevier Rio de Janeiro, 2004

HUIZINGA, Johan. Homo Ludens: o Jogo como Elemento da Cultura. $5^{\mathrm{a}}$ ed. $3^{\mathrm{a}}$ reipr. Ed. Perspectiva. São Paulo 2007.

LEIGH, JAMES H . "The Use of Figures of Speech in Print Ad Headlines." Journal of Advertising 23, 2 (1994): 17-33.

MCQUARRIE, EDWARD F., and DAVID G. MICK.Figures of Rhetoric in Advertising Language. 22,4 (1996): 424-38.

ROMAN, Kenneth. O Rei da Madison Avenue. Cultrix. São Paulo, 2011

AUGUSTO, Regina. Um Ano Complexo e Desafiador. Editorial da Revista Meio \& Mensagem nº1489 Grupo M\&M. São Paulo 2011.

Dicionário Houiass Eletrônico

http://www.radames.manosso.nom.br/retorica/trocadilho.htm

Artigo submetido: 16/01/2012

Artigo aprovado: 17/02/2012 